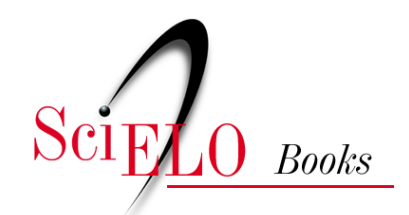

EDUFU

\title{
Performance, teatro e ensino poéticas e políticas da interdisciplinaridade
}

\author{
Eleonora Fabião
}

\section{SciELO Books / SciELO Livros / SciELO Libros}

FABIÃO, E. Performance, teatro e ensino: poéticas e políticas da interdisciplinaridade. In:

FLORENTINO, A., and TELLES, N., eds. Cartografias do ensino do teatro [online]. Uberlândia:

EDUFU, 2008, pp. 61-72. ISBN 978-85-7078-518-3. https://doi.org/10.7476/9788570785183.0007.

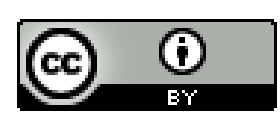

All the contents of this work, except where otherwise noted, is licensed under a Creative Commons Attribution 4.0 International license.

Todo o conteúdo deste trabalho, exceto quando houver ressalva, é publicado sob a licença Creative Commons Atribição $\underline{4.0}$.

Todo el contenido de esta obra, excepto donde se indique lo contrario, está bajo licencia de la licencia $\underline{\text { Creative Commons }}$ Reconocimento 4.0. 


\section{Performance, teatro e ensino: POÉTICAS E POLÍTICAS DA INTERDISCIPLINARIDADE}

Eleonora Fabião

Abordarei aqui aspectos relativos à performance e ao teatro no âmbito da criação e do ensino. Na primeira parte do artigo, introduzo o tema "performance" e na segunda defendo a importância da inserção teórica e prática da performance em contextos de ensino superior de teatro.

Esta reflexão se baseia na minha experiência como performer, atriz, pesquisadora e professora. Assim como as vivencio, as atividades artística, crítico-filosófica e pedagógica são momentos distintos de uma mesma experimentação corporal, política e poética que proponho como performer. A sala de aula, o palco, a rua, a folha de papel, o corpo são dimensões de uma mesma busca: fundar espaços de reflexão e criação onde proponho que nos perguntemos não apenas o que seja "arte contemporânea”, mas o que queremos, contemporaneamente, que a arte seja.

\section{Performance}

Ao longo dos últimos anos coleciono histórias verídicas baseadas nas práticas de artistas que se auto-definem performers. A história do homem que arrastou um bloco de gelo pelas ruas da Cidade do México até seu derretimento completo. A história da mulher que se submeteu a nove cirurgias plásticas combinando em seu rosto traços de nove beldades da pintura ocidental. Do homem que introduziu uma boneca Barbie no ânus e, com controle absoluto de sua musculatura abdominal, expeliu-a lentamente na frente de uma audiência. Ou do homem que se trancou numa cela por um ano e não leu, não falou, não escutou música, não se comunicou com nada nem com ninguém. Este mesmo homem propôs-se a ficar um ano sem adentrar qualquer tipo de espaço coberto, ou seja, passou 365 dias "sem-teto". Este mesmo homem levou a cabo o seguinte projeto: clicar um auto-retrato a cada hora certa, ou seja, 24 vezes por dia, ao lado do mesmo relógio de ponto e no mesmo lugar, ao longo de 12 meses. A história de outro homem que raspou a cabeça, cobriu-a com mel e folhas de ouro, tomou uma lebre morta nos braços e explicou-lhe, silenciosamente, os quadros de sua exibição. E outro que se trancou por 5 dias consecutivos num escaninho $(60 \mathrm{~cm}$ de altura $\times 60 \mathrm{~cm}$ de comprimento $\times 90 \mathrm{~cm}$ de 
profundidade) recebendo água por um tubo e expelindo urina por outro. E outro que convidou amigos para mastigar páginas do célebre Art and Culture, de Clement Greenberg, juntou à polpa ácido sulfúrico, açúcar e bicarbonato de sódio, depositou a mistura num pote que etiquetou com os dizeres "Art and Culture" e retornou o objeto para a biblioteca (perdendo, nesta ocasião, seu emprego como professor na San Martin's School of Art). A mulher que tomou o metrô sábado à noite e foi a uma livraria movimentada vestida com roupas que havia deixado de molho por uma semana num caldo de vinagre, leite, óleo de rícino de bacalhau e ovos. Uma mulher que construiu uma miniatura de palco Italiano, tapou os seios nus com a maquete e convidou os passantes na rua a tocar-lhe os peitos através das cortinas do pequeno palco. A mulher que subiu com os pés descalços uma escada cujos degraus eram feitos de lâminas cortantes. O homem que comemorou seu aniversário na rua, partilhou seu bolo, trocou abraços e recebeu votos de felicidade dos amigos desconhecidos. A mulher que girou uma longa volta (cerca de uma hora de duração) numa praça do Rio de Janeiro. A dupla (um homem e uma mulher) que, por um ano, manteve-se atada pela cintura por uma corda de cerca de dois metros e meio sem tocarem-se. A mulher que convidou os espectadores a usarem nela, enquanto se manteve passiva e parada por seis horas, inúmeros objetos, dentre eles uma rosa, uma pistola, uma bala, tesoura, mel, correntes, caneta, baton, uma câmera Polaroid, faca, chicote e vários outros "instrumentos de prazer e de dor" (os objetos puderam ser utilizados livremente e a performer assumiu plena responsabilidade pelos atos dos espectadores). O homem negro que se sentou numa calçada cinza, exibiu três vidros de maionese branca, e tentou vendê-los por 100 dólares cada. A mulher que, trajando camisolão branco, usou terços para realizar desenhos de pênis no chão. A mulher que perguntou a seus compatriotas palestinos exilados: "Se eu pudesse fazer algo para você, em qualquer lugar na Palestina, o que seria?” E, graças a seu passaporte Americano, cruzou a fronteira inúmeras vezes e atendeu aos pedidos que lhe foram feitos: regar uma planta, pagar uma conta, comer doces, visitar um túmulo, tirar fotografias, jogar futebol com meninos, cheirar o mar ${ }^{1}$.

Estas e muitas outras histórias descrevem programas concebidos e performados por artistas interessados em relacionar corpo, estética e política através de ações intensas e extremas. Gosto de passar estas histórias adiante, de articulá-las em frases curtas, de lançá-las como dardos de adrenalina, sem detalhá-las, sem adjetivá-las, para que cravem secas; estilhaços de mitologia contemporânea. Penso que estas práticas alargam, que estes programas oxigenam e dinamizam nossas maneiras mesmas de agir e de pensar ação e arte contemporaneamente. Esta é, a meu ver, a força da performance: des-automatizar a relação do cidadão com a polis; do agente histórico com seu contexto; do vivente com o tempo, o espaço, o corpo, o outro e consigo mesmo. Esta é a potência da performance: não se trata de operações bizarras e provocativas promovidas por um punhado de sadomasoquistas e idiossincráticos para chocar o "senso-comum" (que aturdido pergunta-se "o que é isso?" "para que isso?" "afinal, o

\footnotetext{
${ }^{1}$ Estas ações foram respectivamente criadas pelos seguintes artistas: Francis Alys (2000), Orlan (anos 90), Denis O'Connor (1999), Theching Hsieh (1978/79, 1981/82 e 1980/81), Joseph Beuys (1965), Chris Burden (1971), John Lathan (1966), Adrian Piper (1970), Valie Export (1968), Gina Pane (1971), Eduardo Flores (2002), Eleonora Fabião (2003), Linda Montano e Theching Hsieh (1983/84), Marina Abramovic (1974), William Pope.L (1991), Márcia X (200003), Emily Jacir (2003).
} 
que eles querem dizer com isso?" "então isso é arte contemporânea?"), mas da expansão da noção de dramaturgia, ou seja, da idéia do que seja ação e "artisticidade" da ação, corpo e "politicidade" do corpo.

Chamo as ações performativas de programas $^{2}$, pois esta me parece a palavra mais apropriada para descrever um tipo de ação metodicamente calculada, conceitualmente polida, que exige extrema tenacidade para ser levada a cabo, e que se aproxima do improvisacional única e exclusivamente na medida em que não será previamente ensaiada. $O$ performer não improvisa uma idéia: ele cria um programa e programa-se para realizá-lo. Ao agir seu programa, necessariamente, des-programa seu organismo e seu meio. Tratam-se de experimentações, de ações "extracotidianas”, da vivência de estados psicofísicos alterados que disseminam dissonâncias diversas: dissonâncias de ordem econômica, política, emocional, orgânica, ideológica, psicológica, espiritual, identitária, sensorial, sexual, social, racial... Programas criam corpos naqueles que os performam e naqueles que são afetados pela performance. Programas anunciam que "corpos" são sistemas relacionais abertos, altamente suscetíveis e cambiantes. Programas geram corpos com proporções que ultrapassam em muito os limites da pele. O performer é um criador de corpos individuais e coletivos, públicos e privados. Se o performer potencializa a relação com seu corpo é para disseminar uma reflexão e uma experimentação sobre a corporeidade do mundo, das relações, do pensamento.

Sugiro que programas performativos baseiam-se em elementos dramatúrgicos discerníveis. Destaco alguns: 1) o deslocamento de referências e signos de seus habitats naturais; 2) a aproximação e fricção de elementos de distintas espécies, naturezas e esferas ontológicas; 3) acumulações, exageros e exuberâncias de todos os tipos; 4) aguda simplificação da forma e condensação de materiais e idéias; 5) a aceleração ou des-aceleração da experiência de sentido até seu colapso; 6) a aceleração ou des-aceleração da noção de identidade até seu colapso; 7) a recusa de performar personagens fictícios e o interesse em explorar características próprias (etnia, nacionalidade, gênero, especificidades corporais), em exibir seu tipo ou estereótipo social; 8) o investimento em dramaturgias pessoais, por vezes biográficas, onde posicionamentos e reivindicações pessoais são publicamente performados; 9) o curto-circuito entre arte e não-arte; 10) o estreitamento entre política e estética; 11) agudez conceitual; 12) o encurtamento ou a distensão da duração até limites extremos; e 13) a ampliação dos limites psicofísicos do performer e de sua audiência;

Porém, veja bem, restrinjo-me a apontar tendências dramatúrgicas genéricas, pois considero vão e mesmo equivocado qualquer esforço no sentido de definir o que seja "performance". Trata-se de uma forma de expressão tão híbrida e flexível que dribla definições rígidas de "arte”, “artista”, “espectador” ou "cena”. Neste sentido, proponho, ao invés de uma investigação sobre o que significa a performance, uma reflexão sobre o que move a performance e o que a performance é capaz de mover. Estrategicamente, a performance escapa a qualquer formatação, tanto em termos das mídias empregadas quanto dos materiais ou espaços utilizados. Como sugere Eduardo Flores numa assertiva propositadamente generalizante, "a matéria

${ }^{2}$ A inspiração para a escolha deste vocábulo vem do texto "Como criar para si um corpo sem órgãos” (DELEUZE, Gilles; GUATTARI, Félix. A thousand plateaus. Minneapolis: University of Minnesota Press, 1987. 107 p.) onde se propõe que o programa é motor de experimentação. 
da performance é a vida, seja do espectador, do artista, ou ambas"3. Flores sugere que a arte opera sempre no sentido de transformar algo, seja matéria em objeto, ou movimento, som, palavra em composição. No caso da performance, a matéria a ser trabalhada é a própria vida. O ofício do performer seria o de "transformar a vida" como sugere Flores, ou ainda, o modo como a vida pode ser vivida. O performer é aquele que evidencia e potencializa a mutabilidade do vivo.

A performance desafia definições, pois ativa dinâmicas paradoxais que complicam estatutos tradicionais tanto do fazer quanto da fruição artística: trata-se da fundação de uma cena-não-cena equiparável ao teatro-não-representacional vislumbrado por Antonin Artaud. É trans-real, pois que move e move-se por múltiplas camadas de sentido sem deixar-se fixar. Artaud preconiza um "teatro da crueldade" sendo que, como explica, "crueldade não é sinônimo de sangue, martírio e inimigos crucificados. Essa identificação de crueldade com vítimas torturadas é um aspecto menor da questão" 4 . Ele esclarece: "Eu disse 'crueldade' como poderia ter dito 'vida' ou 'necessidade"' 5 . O projeto artaudiano, assim como a performance, não visa tampouco a formação de um teatro inconsciente. "Quase o oposto", argumenta Jacques Derrida: "Crueldade é consciência, é lucidez exposta" . A performance, assim como o teatro artaudiano, é cruel na medida em que ativa fluxos paradoxais, ou seja, lógicas que escapam à regulamentação da doxa (senso comum e bom senso); é cruel na medida em que ativa consciência crítica atrelada à consciência corporal, ou seja, ativa consciência como "coisa corpórea". A performance, assim como o teatro de Artaud, é cruel ao minar fundamentos determinantes da cultura ocidental: logocentrismo e tirania teológica. Fundamentos estes que silenciam, anestesiam, minguam nossos corpos; forças de subjetivação que descorporalizam nossas maneiras de nos relacionarmos e criarmos mundo. Como propõe Artaud, o julgamento de Deus precisa ser erradicado para o nascimento do Corpo (self corpóreo); a fúria logocêntrica precisa ser acalmada para o nascimento do Corpo (self corpóreo). Como propóem os performers com seus programas cáusticos, o tipo de conhecimento de que precisamos no presente momento se faz nos Corpos, através dos Corpos, com Corpos, como criação de Corpos. Ou como convoca Gilles Deleuze: "É preciso que estiquemos nossa pele como um tambor para que uma nova política comece".

A partir de uma perspectiva histórica, destaco ainda a (in) definição da "origem” deste gênero. Alguns pesquisadores associam a origem da performance ao teatro de vanguarda europeu do início do século XX - especificamente às práticas cênicas futuristas e dadaístas e ao "Teatro do Absurdo", como sugere RoseLee Gol$\mathrm{dberg}^{8}$. Diferentemente, outros historiadores e teóricos propõem que a origem da

\footnotetext{
${ }^{3}$ Notas tomadas na visita do artista mexicano Eduardo Flores a uma aula do curso "Performance!" que ministrei no primeiro semestre de 2005 como disciplina opcional para alunos de sexto, sétimo e oitavo períodos do curso de Direção Teatral, Universidade Federal do Rio de Janeiro. ${ }^{4}$ ARTAUD, Antonin. Theater and its doublé. New York: Grove Press, 1958. p. 102. Traduzido do inglês.

${ }^{5}$ ARTAUD, 1958, p.114.

${ }^{6}$ DERRIDA, Jacques. A escritura e a diferença. São Paulo: Perspectiva, 1995. p. 165.

7 DELEUZE, Gilles. The logic of sense. New York: Columbia University Press, 1990. p. 72. Traduzido do inglês.

${ }_{8}$ GOLDBERG, RoseLee. Performance art, from futurism to the present. New York: Thames and Hudson, 2001.
} 
performance está relacionada não ao teatro ou à dança, não às artes cênicas, mas a transformações ocorridas nas artes plásticas em meados do século; especificamente à inserção do movimento como elemento da composição plástica e à decorrente e gradual des-materialização do objeto de arte. Fato é que a valorização da ação resultou num encontro do artista com seu próprio corpo, num confronto com a materialidade de sua presença que se tornou material de trabalho. $\mathrm{Ou}$, como se convencionou dizer, o artista tornou-se sujeito e objeto de sua obra. De acordo com esta perspectiva, o marco de origem das práticas performativas teria sido a action painting norte-americana e experimentos correlatos acontecendo em outros países protagonistas da Segunda Guerra Mundial, especificamente na Ásia e na Europa como sugere Paul Schimmel' . De fato, enquanto gênero, a performance começa a adquirir feições mais definidas depois da Segunda Guerra Mundial e suas catástrofes correlatas. A experiência de morte massiva e, significativamente, a experiência da explosão atômica, foram referências determinantes para um certo entendimento de "corpo", "comunicação" e "experiência” investigado por performers. A partir de então, começaram a espocar pelo mundo afora séries de práticas difíceis de classificar, a maioria delas envolvendo o corpo do artista de forma inédita e radical, baseadas em aguda materialidade e força conceitual.

Entretanto, seja afirmando que a performance originou-se a partir ou de práticas cênicas ou de práticas plásticas, muito pouco muda em relação ao estatuto artístico da performance e sua inserção na tradição cultural ocidental. Este é o argumento de Thomas McEvilley em "Stages of Energy: Performance Art Ground Zero?" 10 . Neste artigo, o autor defende a idéia de que a performance é uma forma de recusa aos valores e procedimentos da arte ocidental, ou, mais enfaticamente, uma ruptura e um afastamento desta tradição. McEvilley sugere que o "novo gênero" se originou em manifestações rituais antiqüíssimas, práticas que o autor define como "pré” ou "extra" civilizatórias.

Pessoalmente penso que uma discussão sobre a "origem" da performance é interessante apenas na medida em que se mantém aberta. Se consideramos o caráter eminentemente híbrido do fato performativo, ter de optar se foi a pintura, a dança, o teatro ou qualquer gênero artístico o berço da performance, soa redutor. Diferentemente de McEvilley, não penso que a performance represente uma refuta mas uma contrapartida a valores predominantes da cultura ocidental contemporânea - nomeadamente: reprodutibilidade, eficiência, eficácia, efetividade, durabilidade, segurança identitária e material, conforto e solidez - sem contudo deixar de ser um componente cada vez mais importante da nossa cultura. A performance atualmente é referência contundente, ainda que marginal; é prática marginal, ainda que contundente ${ }^{11}$.

\footnotetext{
9 SCHIMMEL, Paul (Org.) Out of actions: between performance and the object 1949-1979. Los Angeles: Tharus and Hudson, The Museum of Contemporary Art, 1998.

10 McEVILLEY, Thomas. Stages of energy: performance art ground zero? In: Artist's body. Milano: Charta, 1998.

${ }^{11}$ Não percebo, por exemplo, uma rejeição, mas uma relação conturbada com valores de mercado. A performance participa, ainda que como crítica e recusa, da economia reprodutiva e do mercado de arte. Basta pensarmos no frisson editorial, na quantidade de catálogos, livros, exposições de documentos e relíquias de performances, na quantidade de souvenirs, postais, canecas decoradas e DVDs dedicados à "mais efêmera das artes".
} 


\section{Performance e ensino de teatro}

A pergunta é direta: por que considero fundamental, contemporaneamente, ensinar, ou ainda, instigar o debate e a prática da performance em contextos de ensino superior de teatro? E de que maneira uma aproximação pedagógica entre performance e teatro pode beneficiar estudantes de teatro ${ }^{12}$ ?

Fato é que entrecruzamentos entre teatro e performance são moeda corrente nos palcos contemporâneos. Grupos de teatro experimental como o britânico Forced Entertainment, os norte-americanos Wooster Group e Goat Island, ou os brasileiros Teatro da vertigem e Companbia dos atores ${ }^{13}$, bem como Denise Stoklos e seu Teatro essencial, para citar alguns casos, desenvolvem trabalhos influenciados e/ou consonantes com estéticas e éticas performativas. Em nível pedagógico, porém, o ensino da performance em cursos de teatro no Brasil ainda é prática embrionária e precisa ser cuidadosamente discutido.

Considero a inserção da prática e da teoria da performance no circuito pedagógico teatral estimulante por vários motivos e destaco alguns dos principais: 1) sofisticação de pesquisas corporais; 2) ampliação do repertório de métodos composicionais; 3 ) investigação de linguagens e dramaturgias não-convencionais e hibridação de gêneros artísticos; 4) discussão de questões cênicas através de outro viés que não os da teoria do drama ou das histórias e poéticas espetaculares; 5) aprofundamento de debates e práticas teatrais focados em políticas de identidade e em políticas de produção e recepção cada vez mais articuladas e acutilantes; 6) valorização da investigação sobre dramaturgias do espectador. Estes serão os temas abordados ao longo das próximas páginas.

Para o aluno de teatro em geral (não apenas futuros atores, mas também futuros diretores, professores e teóricos) penso ser de extrema valia confrontar-se com experiências psicofísicas baseadas na tradição da performance. Tais vivências (para usar o termo cunhado por Lygia Clark e Hélio Oiticica nas fases de seus trabalhos voltadas para a expansão da sensorialidade do espectador) visam à desconstrução de hábitos cotidianos (e automatismos teatrais). A proposta consiste em operar mudanças radicais nas dinâmicas espaços-temporais habituais para que outros estados psicofísicos possam aflorar. Trata-se de uma oportunidade para o aluno abrir horizontes perceptivos insuspeitados, aprofundar autoconhecimento e questionar-se a respeito de padrões culturais e sociais.

\footnotetext{
12 Nos últimos anos leciono cursos e workshops em performance para fazedores de teatro e dança em diversas instituições e países, em nível de graduação e pós-graduação. Ser professora é parte do meu projeto artístico. Considero estes cursos performances em si, programas que realizo com grupos de alunos através de uma pedagogia relacional. Como ensinadora da performance, proponho diversas experiências psicofísicas bem como a leitura e debate de textos históricos e filosóficos, e aponto técnicas de composição para que os participantes criem peças. Não trabalho propondo exercícios em performance ou conduzindo ensaios para a realização de futuras peças. Sou uma propositora de experiências. Como professora-performer, meu trabalho é propor e vivenciar experiências. Tais experiências visam o desenvolvimento e a integração das capacidades orgânicas, criativas e comunicacionais do atuante (performer, cidadão, sujeito histórico, vivente) e visam seu fortalecimento através do aumento de agilidade, flexibilidade e disponibilidade. Considero a sala de aula um dos mais interessantes espaços performativos, pois que estabelecemos, de antemão, um pacto colaborativo. Trata-se de um espaço de criação e experimentação, um microcosmo político a ser poeticamente e pedagogicamente explorado.

13 No caso da carioca Cia. dos atores, percebo este tônus performativo especificamente numa montagem recente: Ensaio. Hamlet.
} 
Não se trata de focar na criação de personagens ou na exploração de técnicas interpretativas ou jogos improvisacionais, mas de acessar algo que antecede, que enerva atuação e atuante. Trata-se de um confronto do fazedor de teatro com sua psicofisicalidade, com sua metafisicalidade, com seu Corpo e história; confronto este que, penso, sofisticará enormemente a relação com personagens, parceiros de equipe, espaços, objetos, espectadores, conceitos. Como propôs Grotowski "O Performer, com maiúscula, é o homem de ação. Não é o homem que faz o papel do outro. É o dançante, o sacerdote, o guerreiro: está fora dos gêneros estéticos. [...] Pode compreender apenas se faz. Faz ou não faz. O conhecimento é um problema de fazer" ${ }^{14}$.

Aqui, interessa evocar as formas de conbecimento ativo do grupo paulista Teatro da Vertigem. Interessa como o Vertigem investe em mecanismos dramatúrgicos de alta voltagem performativa para a criação de seus espetáculos ${ }^{15}$. $O$ grupo privilegia o que chamo dramaturgia do ator, ou seja, processos criativos onde o ator não é exclusivamente um intérprete, mas um co-autor do espetáculo assim como o diretor, o cenógrafo, o iluminador, o figurinista e todos os demais membros da equipe que, geralmente coordenados por um diretor, colaboram para a criação da dramaturgia do espetáculo. Ou, como os atores do Vertigem definem sua função, o ator "é simultaneamente autor e performer" ${ }^{16}$. No artigo "O que fazemos na sala de ensaio" os atores-autores-performers do Vertigem destacam a importância do que chamam "depoimento pessoal": "Depoimento pessoal é sua colocação como ser humano, como cidadão e artista. [...] É deixar que sua experiência vire arte, seja manipulada"17, esclarece Mariana Lima. Como dizem, não estão interessados em “camuflar características, mas ampliá-las"18.

Quanto aos métodos de ensaio, composição de cena e personagens, o grupo destaca quatro modalidades de práticas: a vivência (método que se aproxima do laboratório teatral, sempre pontuado com atividade de escrita automática), a improvisação (improvisações sem preparo prévio a partir de materiais diversos relacionados com o tema pesquisado), os workshops (cena-resposta a uma questão lançada, composição a ser preparada de um dia para outro utilizando qualquer tipo de mídia) e as visitas (pesquisa de campo, sempre em espaços públicos, a partir da qual o ator elabora cenas e/ou personagens).

Atrelada à pesquisa dramatúrgica em sala de ensaio há outro elemento determinante: o interesse em ocupar espaços não convencionais ${ }^{19}$. "A apresentação em lugares impróprios para o aconchego do público ou para o conforto dos atores abre outras possibilidades, que reinventam o teatro não apenas como entretenimento, mas como experiência" ${ }^{20}$. Refletindo sobre a relevância destes espaços ativos para o desenvolvimento de suas práticas teatro-performativas afirmam: "A relação

${ }^{14}$ REVISTA MÁSCARA. Cidade do México: Fondo de Cultura del México, [19--] p. 78. Número especial em homenagem à Jerzy Grotowski.

${ }^{15}$ Refiro-me à criação e encenação da Trilogia bíblica composta pelas peças $O$ paraíso perdido (1992), O livro de Jó (1995) e Apocalipse 1,11 (2000). NESTROVSKI, Arthur (Org.). Trilogia bíblica: teatro da vertigem. São Paulo: Publifolha, 2002. 359 p.

16 "O que fazemos na sala de ensaio" em NESTROVSKI, 2002, p. 45.

17 NESTROVSKI, 2002, p. 46.

${ }_{18}$ NESTROVSKI, 2002,

19 No caso da Trilogia bíblica, respectivamente, igreja, hospital e presídio.

20 NESTROVSKI, 2002, p. 48, destaque nosso. 
com o público é conseqüência de uma situação híbrida em que representação e realidade se confundem" ${ }^{21}$. A criação de uma cena híbrida onde elementos fictícios e não-fictícios são justapostos, a ativação política provocada por tal justaposição, a ocupação de espaços "extracênicos" (para que possam circular outras dinâmicas relacionais), a ampliação de características pessoais (em busca de uma dramaturgia pessoal, por vezes biográfica), a valorização da experiência e da experimentação psicofísica através dos métodos criativos utilizados, a valorização do ator-dramaturgo e do artista-etnógrafo, são elementos marcadamente performativos explorados pelo Teatro da Vertigem. Grupo que, como o próprio nome diz, não pretende um teatro de estabilidade ou uma relação confortável com a "cena".

Da mesma forma, a performance. Sua inserção no âmbito de ensino do teatro causará algum desconforto e desassossego, mas, seguramente, proporcionará fricções interdisciplinares de enorme valia. Por posicionar-se como uma prática "antiteatral" - ou seja, desinteressada nos espaços teatrais, métodos criativos, funções especializadas, possíveis hierarquias nas equipes, poéticas e economias de ensaio e repetição - a performance representa um referencial dialógico fascinante (no mínimo uma pedra no sapato que nos faz parar, descalçar, sacudir, e voltar a caminhar com novas percepções do pé, do terreno em que se pisa, do calçado que se escolhe usar, ou seja, das relações entre corpo, objeto e meio). Um performer não apenas coloca propositadamente pedras em seu sapato, mas usa sapatos de pedra para que os fluxos ditos "naturais" sejam interrompidos e outras maneiras de percepção e relação possam se desenvolver. Muito me interesso pelo valor crítico-pedagógico de atos que suspeitam dos "padrões de normalidade".

Penso que o aluno de teatro se beneficia não apenas no contato prático, mas no estudo da teoria da performance através do qual poderá refletir sobre aspectos centrais do teatro do século XX. Interesssa por exemplo, à luz da performance, abordar temas como o ilusionismo (construção e demolição) e a narrativa ficcional (adesão e desconstrução). A performance, em sua aguda materialidade, des-narrativização, antificcionalidade e instantaneidade, ou seja, por operar em extrema oposição ao ilusionismo e ao narrativismo, torna-se uma referência importante para um certo teatro contemporâneo interessado em discutir seus espaços de atuação, políticas de produção e recepção, noções de corporeidade e dramaturgia.

Este é o caso do grupo de teatro Forced Entertainment (Entretenimento Forçado), especificamente em suas peças de longa duração. O grupo expõe o projeto:

Depois de anos fazendo teatro, em que uma parte do trabalho consistia em ensaiar e fixar coisas - fazer a mesma peça funcionar da mesma maneira repetidas vezes - nós resolvemos fazer algo diferente, algo mais extremado. As peças longas foram um passo nessa direção: trabalhos entre seis e vinte e quatro horas de duração nos quais os atores improvisam dentro de um sistema pré-definido de regras. [...] Considere cada peça como uma tarefa ou um jogo [...] e considere que cada jogo tem regras, estratégias, movimentos conhecidos e também limites ${ }^{22}$.

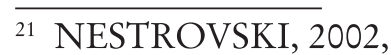

22 "Notas sobre as peças de longa duração" em * HEATHFIELD, Adrian. (Ed.). Live art. Mustang: Tate Publishing, 2004. p. 101. Traduzido do inglês.
} 
Um destes trabalhos - Quizoola!, um jogo de perguntas e respostas para dois participantes - tem a duração de seis horas. O público está livre para entrar e sair quando e quanto quiser. Três atores da companhia explorando as três combinações de dupla possíveis, revezam-se por períodos de duas horas. Os atores interrogam-se mutuamente baseados num questionário com duas mil perguntas sobre os mais variados temas - esportes, história, amor, filosofia, fatos... Como explicam, as respostas podem ser verdadeiras, falsas, longas, curtas, confessionais, abstratas, de acordo com decisões imediatas. O design da cena é extremamente simples. Lâmpadas elétricas ligadas em série formam um círculo no chão que delimita o espaço do jogo. Os atores estão vestidos com roupas cotidianas e maquiados como palhaços. Duas cadeiras, as folhas de papel com as perguntas e algumas garrafas d'água pontuam o quadro.

Em Quizoola! não há vestígio de narrativa, ficção, personagem ou qualquer espécie de mediação dramática. O "fechamento" da cena circunscrito pelas lâmpadas no chão é meramente alegórico: a cena chega aos espectadores de forma direta através de interpretações abertas (ou seja, através de atores não apenas cientes da presença dos espectadores, mas capazes de transformá-los em elementos da ação se assim desejado). A dramaturgia da peça é outro elemento de abertura: cada vez que uma pergunta é lançada abre-se um vácuo que é imediatamente ocupado mentalmente pelos espectadores. A cada interrogação suspensa, um salto mental. A longa duração da peça tanto exaure como exalta atores e espectadores fazendo daquela cena uma experiência psicofísica única. Por vezes, a argüição é cômica e amigável; em outros momentos, transforma-se numa forma de tortura; noutros, adentra-se um espaço desarticulado, demente, vazio, disléxico, mole. Os semblantes de palhaço oscilam significação de acordo com a atmosfera da cena. Quizoola! é um jogo de perguntas e respostas a partir de uma interrogação essencial: quais os limites da cena teatral?

Esta é uma interrogação fundamental para o aluno interessado tanto em aprender técnicas e tradições quanto em posicionar-se crítica e criativamente em relação à tradição e seu arcabouço técnico e teórico. A performance sugere que parte do aprendizado é inserir-se na tradição e dialogar com ela, e parte do aprendizado é forçar limites preestabelecidos e criar ruídos. Ou, em outras palavras, parte do estudo é conhecer o teatro e parte do estudo é perguntar-se sobre o que seja "teatro".

Penso que interessa particularmente ao aluno de teatro - num momento histórico em que outras mídias dramáticas (industriais, eletrônicas, digitais) exigem um investimento nas especificidades da cena da presença compartilhada - uma reflexão diretamente voltada para a dramaturgia do espectador como aquela proposta pela performance. Se o espetáculo teatral é único em cada apresentação, e de fato é, a performance acirra ainda mais a efemeridade da presença e a precariedade do evento: a performance é radicalmente irrepetível. O imediatismo da performance deve-se justamente à falta de elementos de mediação, seja o enredo, o personagem ou o palco. Conforme dito anteriormente, a performance funda uma cena com características muito particulares uma vez que propõe a realização de ações não-fictícias em tempo "real". Ou ainda, a performance distende a idéia de "cena" propriamente dita: do drama do palco passamos ao drama da sala, da rua, da cidade. A "cena” performativa trata da execução de programas psicofísicos e da vivência das relações que estes 
programas deflagram (relações consigo, com o outro, com o objeto, com o meio). $E$ É determinante o fato de que o decréscimo ficcional, ilusionista e narrativo implica num acréscimo de presença e participação do espectador. $\mathrm{O}$ espectador torna-se um elemento fundamental na trama performativa, um agente direto ou indireto, uma testemunha, ou, por vezes, um co-autor da ação proposta pelo performer. Comemorar o aniversário de um desconhecido na rua, abraçá-lo, desejar-lhe sinceros ou insinceros votos de felicidade e comer do seu bolo; ver uma pessoa cortar-se e não impedi-la; interferir com objetos que provocam dor ou prazer no corpo de um alguém desconhecido e passivo; comprar ou não um vidro de maionese por 100 dólares; divertir-se ou chocar-se com o fato de que uma pessoa transforma seu próprio rosto, a cirurgia plástica e o set cirúrgico num circo macabro; indignar-se ou não com um cidadão que decide, não por falta de recursos, transformar-se temporariamente num sem-teto e chamar isso "arte"; revoltar-se ou rir com outro que esculpe caralhos com terços; optar por tocar ou não nos seios de uma mulher através das cortininhas de um teatro à italiana são provocações que implicam não num ensaio psicológico de posicionamento, mas em tomadas de posição imediatas. $\mathrm{O}$ chamado da performance é justamente este: posicione-se já, aqui e agora. Chamado este que instiga no aluno de teatro um posicionamento político consciente e ativo e aponta para a importância da dramaturgia do espectador, ou seja, para as maneiras como o teatro ativa seu público.

Entretanto, é preciso esclarecer: mesmo abolindo a ficção, não escapamos da narrativa, visto que o processo de cognição humana é fortemente narrativo. A desaceleração narrativa tampouco elimina por completo a dimensão representacional, pois como ressaltado anteriormente, estamos tratando de cenas, ainda que imediatas e cruas. Porém, ao esvaziarmos ao máximo a narratividade de um evento, sua condição de decifração através de um ato de "leitura" será minimizada em favor de uma experiência relacional com o mesmo. Conforme proposto na primeira parte deste ensaio, não penso que a melhor maneira de acessar o evento seja definindo o significado ou significados da ação performada, mas buscando perceber qual seja sua força motriz e que novas forças daí se repercutem. (Definir o que significa um sujeito arrastando um bloco de gelo pela Cidade do México ou alguém rodando por um longo período de tempo numa praça pública do Rio de Janeiro me parece menos importante e interessante do que atentar para as motivações dramatúrgicas e políticas de seus agentes e para as ações e reflexões que se derivam nos que experimentam tais programas - seja assistindo, performando ou ouvindo falar).

E neste ponto adentramos, talvez, a maior zona de turbulência ativada pela performance: sua maneira de operar "comunicação". Como sabemos, o conceito de comunicação sofreu significativas alterações quando se flexibilizaram as noções de sujeito, objeto, linguagem, meio, corpo... (com Einstein, Freud, Heisenberg, Merleau-Ponty, Beckett e tantos outros que demonstraram como o relativismo, a inconsciência, a indeterminação, o paradoxo e o vazio são forças constitutivas da experiência comunicacional). A ilusão da comunicação como transmissão mecânica de uma mensagem - que trafega invariável entre emissores e receptores de forma transparente e inequívoca -espatifou-se. O temido 
"ruído" tornou-se elemento paradoxicalmente comunicacional, elemento incluído por vários artistas em seus discursos. O performer não pretende exatamente comunicar um determinado conteúdo ao espectador, mas, acima de tudo, promover uma experiência através da qual conteúdos serão elaborados. Em geral, o foco não está na transmissão de determinado conteúdo, mas na potência relacional promovida pela experiência proposta (no caso do espectador, na experiência que este estabelece com o performer, consigo, com os outros da audiência, com o espaço onde a operação se dá e seu contexto histórico). É sobretudo neste conteúdo relacional que reside a força política do ato performativo. Para os estudantes de teatro, o desafio lançado pela performance (e todas as práticas que provocam distúrbios comunicacionais) é direto: como o teatro vem tratando destas questões e quais as conseqüências éticas e estéticas destas manobras? Trata-se igualmente de uma pergunta-chave para professores de teatro, ocupados em liderar cenas comunicacionais abertas a tantas correntes interdisciplinares como a sala de aula de teatro.

Por fim, penso que especificamente em nosso país, um país marcado tão profundamente por atos de violência e de irresponsabilidade política, a aproximação entre performance e teatro indica caminhos prolíficos para uma renovação da discussão política da e na cena brasileira. Como, depois do apogeu da era Bertolt Brecht, estamos articulando nossas poéticas políticas? Como a cena contemporânea responde às políticas da globalização "pós-colonial”? Ao refletir sobre a verve política da arte contemporânea, Lucy Lippard esclarece:

Está claro que hoje em dia até a arte existe como parte de uma situação política. O que não quer dizer que a arte tem de ser vista em termos políticos ou ser explicitamente engajada, mas a maneira como os artistas tratam sua arte, onde eles a fazem, as chances que se tem de fazê-la, como ela será veiculada e para quem - é tudo parte de um estilo de vida e de uma situação política ${ }^{23}$.

Ou seja, tratar-se ou não de militância política, não é o ponto nevrálgico do problema. O chamado é por uma ativação da consciência política, a noção de que participamos de um contexto histórico e, sobretudo, de que nossos atos formam tal contexto. A performance é a arte da negociação.

Espero que ao fim deste artigo estejam claros alguns dos principais motivos pelos quais penso que a performance deva ser incluída nos currículos de teatro em nível superior de ensino. Espero que esta discussão se fortaleça na academia assim como vem fortificando-se nos palcos e festivais de teatro pelo mundo afora. A interdisciplinaridade não é um modismo, mas um caminho contemporâneo de potencialização política e poética.

${ }^{23}$ LIPPARD, Lucy R. Six years: the dematerialization of the art object. Berkley: University of California Press, 1973. p. 8-9. Traduzido do inglês. 


\section{REFERÊNCIAS}

ARTAUD, Antonin. Theater and its doublé. New York: Grove Press, 1958.

DELEUZE, Gilles. The logic of sense. New York: Columbia University Press, 1990.

DELEUZE, Gilles; GUATTARI, Félix. A thousand plateaus. Minneapolis: University of Minnesota Press, 1987.

DERRIDA, Jacques. A escritura e a diferença. São Paulo: Perspectiva, 1995.

GOLDBERG, RoseLee. Performance art, from futurism to the present. New York: Thames and Hudson, 2001.

HEATHFIELD, Adrian. (Ed.). Live art. Mustang: Tate Publishing, 2004.

LIPPARD, Lucy R. Six years: the dematerialization of the art object. Berkley: University of California Press, 1973.

McEVILLEY, Thomas. Stages of energy: performance art ground zero? In: Artist's body. Milano: Charta, 1998.

NESTROVSKI, Arthur (Org.). Trilogia bíblica: teatro da vertigem. São Paulo: Publifolha, 2002.

REVISTA MÁSCARA. Cidade do México: Fondo de Cultura del México, [19--]. Número especial em homenagem à Jerzy Grotowski.

SCHIMMEL, Paul (Org.) Out of actions: between performance and the object 1949-1979. Los Angeles: Tharus and Hudson, The Museum of Contemporary Art, 1998. 